\title{
Construção de instrumentos teórico-metodológicos para captar a formação de professores'
}

Daniela Gonçalves de Abreu"

Manoel Oriosvaldo de Mourall'

I- Agradecemos à escola estadual que participou da realização deste trabalho e aos professores que aceitaram participar do grupo e que, aos poucos, tornaram-se parceiros muito valiosos. II- Universidade de São Paulo, Ribeirão Preto, SP, Brasil.

Contato: danielaga@ffclrp.usp.br

III- Universidade de São Paulo, São Paulo, SP, Brasil.

Contato: modmoura@usp.br

\section{Resumo}

A pesquisa sobre o perfil do educador ambiental tem exigido uma metodologia de investigação adequada para a captação de seu processo de formação. Dado que ao pesquisar a formação de professores estamos diante de algo que não está posto materialmente e tem caráter dinâmico, de que modo tomar a formação do educador ambiental como objeto de pesquisa? Para a construção de uma resposta a essa pergunta, o presente trabalho requereu instrumentos teóricos e metodológicos que possibilitassem apreender a formação do professor em sua atividade educativa. A formação do educador ambiental pressupõe um ambiente em que todos tenham voz e possam trocar experiências, rever seus conhecimentos e produzir novos sentidos a partir de uma perspectiva crítica. A constituição de uma comunidade de aprendizagem numa escola pública estabeleceu um contexto propício para a formação dos professores. Pudemos comprovar que o Horário de Trabalho Pedagógico Coletivo, quando planejado e organizado, pode intencionalmente contribuir para a formação de professores. A teoria da atividade nos forneceu subsídios tanto do ponto de vista de ensino, ao proporcionar embasamento para a organização de encontros com professores de ensino médio, sempre levando em conta a intencionalidade da formação, quanto do ponto de vista metodológico, ao possibilitar a apreensão de nosso objeto, ou seja, o processo de formação em seu movimento. Na interação entre os sujeitos, foi possível a ampliação de seus pontos de vista e a ocorrência de mudanças de sentidos relacionados a temas ambientais. Um sujeito, ao evocar um pensamento, uma reflexão, possibilita que os demais revisitem seus posicionamentos e conhecimentos. Assim, formam-se conhecimentos - e, consequententemente, indivíduos com qualidade nova.

\section{Palavras-chave}

Formação - Professores - Objeto de pesquisa - Teoria da atividade - Educação ambiental - Escola. 


\section{The construction of theoretical and methodological tools to capture teacher education'}

Daniela Gonçalves de Abreu"

Manoel Oriosvaldo de Mourall"

I- We thank the state school that participated in this work and the teachers who agreed to participate in the group and gradually became very valuable partners. II- Universidade de São Paulo, Ribeirão Preto, SP, Brasil.

Contact: danielaga@ffclrp.usp.br

III- Universidade de São Paulo, São

Paulo, SP, Brasil.

Contact:modmoura@usp.br

\begin{abstract}
Research on the profile of environmental educators has required a research methodology appropriate for capturing their training process. As when researching teacher education we are before something that is not materially established and is dynamic, how can one take the training of environmental educators as a research object? To construct an answer to this question, this study required theoretical and methodological tools that enabled grasping the training of teachers in their educational activities. The training of environmental educators requires an environment in which everyone has a voice and can share experiences, review their knowledge and produce new meanings from a critical perspective. The creation of a learning community in a public school established a favorable context for teacher education. We confirmed that, if planned and organized, Horário de Trabalho Pedagógico Coletivo (Collective Pedagogical Worktime) can intentionally contribute to teacher education. Activity theory offered resources both from the point of view of teaching, by providing a basis for the organization of meetings with secondary school teachers, always taking into account the intentionality of training, and from the methodological point of view, by allowing us to grasp our object, that is, the training process in its movement. In the interaction between subjects, they were able to expand their views and there were changes of meanings related to environmental issues. By evoking a thought, a reflection, subjects enable the others to revisit their positions and knowledge. Thus, knowledge is formed with new quality and so are individuals.
\end{abstract}

\section{Keywords}

Training - Teachers - Research object - Activity theory Environmental education - School. 
No período de 2006 a 2008, dedicamo-nos a investigar de que forma a educação ambiental estava presente em cursos de formação inicial de professores de química. As investigações se centraram no currículo prescrito e, posteriormente, no currículo percebido por graduandos de diferentes cursos de licenciatura em química. Em relação ao currículo prescrito (SACRISTÁN, 2000), procuramos encontrar indícios sobre a abordagem de conteúdos ligados à temática ambiental na formação inicial de professores de química, por meio da análise de programas e ementas de disciplinas de química e ensino de química que são oferecidas tanto no curso de licenciatura em química da Faculdade de Filosofia, Ciências e Letras de Ribeirão Preto, Universidade de São Paulo, como também em outros cursos do mesmo tipo no estado de São Paulo.

Mais tarde, visando a investigar a percepção de licenciandos em química de outras universidades sobre sua formação em temas ambientais, um roteiro contendo questões foi elaborado e enviado via internet para 21 alunos do último ano de cursos de licenciatura em química nas universidades públicas paulistas. Os alunos foram previamente contatados por telefone ou e-mail, tendo sido a maioria deles indicada por professores. Textos foram elaborados pelos estudantes a partir do roteiro e realizou-se a análise do conteúdo (BARDIN, 2006).

Os estudantes citaram várias disciplinas, como química analítica, química inorgânica, química orgânica, bioquímica, noções de segurança em laboratório e química ambiental. Segundo eles, seus professores abordaram de alguma forma temas ambientais durante a graduação (GIUBINA; CAMPOS; ABREU, 2008). Os entrevistados destacaram a abordagem de tratamento e descarte de resíduos químicos e as citações se referiam, na maioria das vezes, a riscos e imprudências de se descartarem resíduos na pia do laboratório. Os estudantes também mencionaram que a discussão do referido tema muitas vezes se restringe aos aspectos científicos.

A partir dos dados levantados, foi possível constatar a forte vinculação entre o tra- tamento de resíduos e a temática ambiental na formação de professores de química. Acreditamos que a abordagem de questões complexas de maneira restrita aos aspectos meramente tecnológico-científicos torna-se não só insuficiente e redutiva para a resolução das questões ambientais, como ainda leva ao risco de uma concepção falsa e distorcida, justamente aquela em que se aceita, sem um maior espírito crítico, que qualquer intervenção predatória do homem possa ser favoravelmente modificada tão somente pelo avanço do conhecimento científico, ignorando-se, portanto, a conditio sine qua non de uma nova postura cultural (no sentido de revermos nossos hábitos e costumes, nosso cotidiano e nossas normas até aqui irresponsáveis em relação ao meio ambiente). Apesar de considerarmos a abordagem sobre resíduos importante, acreditamos que ela seja um primeiro passo para abordagens mais amplas que incluam não somente os aspectos tecnológico-científicos, mas também aspectos sociais, culturais, políticos e econômicos.

Pelos levantamentos e pelas análises realizadas até dezembro de 2009 , já tínhamos reunido indícios suficientes sobre como a educação ambiental está presente na formação dos professores. Acreditando no potencial da pesquisa como elemento transformador dessa realidade, decidimos propor uma investigação que fosse além de simplesmente constatar o panorama. Essa pesquisa deveria contribuir para solucionar os problemas e as deficiências já identificadas. Nesse sentido, em janeiro de 2010, se estabeleceu-se uma parceria com uma escola pública de Ribeirão Preto, com a intenção de constituir um grupo de estudos sobre temas ambientais no qual pudéssemos contribuir para a formação dos professores de ensino médio em educação ambiental e, ao mesmo tempo, pesquisar o processo dessa formação. Mas como pesquisar um objeto que é dinâmico? Como apreender suas características e dinâmicas? Nesse sentido, um estudo sobre a perspectiva histórico-cultural e, em particular, sobre a teoria da atividade foi realizado, buscando-se 
identificar instrumentos teórico-metodológicos capazes de subsidiar a investigação em questão: a formação do professor.

A partir de 2010, organizamos encontros com professores de ensino médio de uma escola pública de Ribeirão Preto. Os encontros foram realizados na instituição, como parte de uma atividade na qual a necessidade era formar educadores ambientais. 0 motivo era propiciar que os professores tivessem conhecimento sobre a educação ambiental e a tomassem como objeto de ensino. Ao planejar o ensino e a aprendizagem, definir as ações educativas, eleger os instrumentos mediadores dessas ações e um modo para avaliá-las, o professor tinha a possibilidade de vivenciar o ensino como uma atividade, já que aquele tinha a estrutura de uma atividade segundo concebe Leontiev (1978). Dessa forma, no presente artigo, apresentamos e discutimos o potencial da teoria da atividade na formação de professores, bem como relatamos dados e uma análise sobre possibilidades formativas.

\section{Contribuições da perspectiva histórico-cultural}

Para alguém cujo objeto de pesquisa é a formação, cabe a pergunta: como o ser humano aprende? Como ele se desenvolve? São muitas as respostas e sabemos quanto o desenvolvimento científico tem contribuído para lhes dar precisão. Ao tomarmos como referência a perspectiva histórico-cultural, assumimos os pressupostos vigotskianos que ressaltam o papel das interações dos sujeitos em seu meio, mediadas por artefatos culturais que lhes possibilitam a apropriação de conceitos construídos historicamente. Essa perspectiva se origina a partir do materialismo histórico-dialético com base na filosofia marxista, a qual supõe que o ser humano, ao transformar a natureza, transforma a si próprio e cria condições para o desenvolvimento histórico e social. Vigotski (1989, 1998), ao questionar concepções sobre os processos humanos de aprendizagem, acrescenta na relação sujeito-objeto a mediação. Ou seja, para esse autor, tal interação é mediada e, em especial, é feita por signos e num movimento da esfera interpsíquica (campo das relações) para a esfera intrapsíquica (sujeito). Vigotski também propõe o que chama de zona de desenvolvimento proximal (ZDP), que contém funções ainda em processo de maturação, mas já presentes em estado embrionário. Pressupomos que a interação entre os indivíduos seja fundamental na constituição do ser humano, pois a relação interpessoal poderá interiorizar as formas culturalmente estabelecidas de funcionamento psicológico. Segundo a perspectiva vigostskiana, atuar na ZDP e promover a interação interpessoal do professor com alunos e colegas é fundamental para favorecer o desenvolvimento.

Os psicólogos soviéticos elegeram o conceito de atividade como um dos princípios centrais do estudo do desenvolvimento do psiquismo. Entendidas como uma unidade dialética, consciência e atividade são consideradas dois elementos fundamentais à psicologia histórico-cultural. A teoria da atividade surgiu no campo da psicologia, com os trabalhos de Vigotski e Leontiev. Ela pode ser considerada um desdobramento do esforço para a construção de uma psicologia sócio-histórico-cultural fundamentada na filosofia marxista (GOLDER, 2004).

Já em seus primeiros escritos, Vigotski utilizou o conceito de atividade e sugeriu que a atividade socialmente significativa é o princípio explicativo da consciência por meio das relações sociais. Leontiev (1978) se propôs a estudar como a estrutura da consciência do homem se transforma de forma interdependente com a estrutura da atividade que desenvolve.

As relações entre o sujeito e o objeto, entre estímulo e resposta, estão mediadas pela atividade e dependem das condições, dos objetivos e dos meios. A primeira condição de toda atividade é uma necessidade, e a atividade humana tem como característica principal seu caráter objetal, que deve ser entendido em forma relacional a um objeto que, seja real ou realizável, torna-se motor da ação de um sujeito. Por exemplo, se o indivíduo está com 
sede e a necessidade é saciar a sede, ele só poderá entrar em atividade se o objeto água estiver disponível.

É conhecido o exemplo da caçada que Leontiev usa para ilustrar o conceito de atividade (DUARTE, 2004), o qual apresentamos sinteticamente a seguir. Imagine que os homens primitivos tivessem fome; a necessidade, então, seria saciar a fome. A partir do momento em que o objeto mamute se torna disponível, é possivel entrar em atividade, ou seja, torna-se possivel articular ações, objetivos e operações em razão de saciar o problema coletivo (fome).

Observamos que o motivo é o que impulsiona uma atividade, pois articula uma necessidade a um objeto. Necessidade, objeto e motivo são componentes estruturais da atividade. Esta não pode existir senão pelas ações. No caso da caçada, os homens no grupo terão diferentes funções e ações, de acordo com suas habilidades e preferências. Porém, todas as ações estão vinculadas à necessidade mobilizadora (saciar a fome). As ações apresentam, além do aspecto intencional, o aspecto operacional, isto é, a forma como se realizam as operações. Resumindo, poderíamos dizer que a atividade é constituída a partir de um motivo desencadeador das ações concretizadas por meio de operações, que dependerão das condições objetivas oferecidas pelo ambiente no qual a atividade se realiza.

Sforni (2004), em seus estudos sobre a teoria da atividade, afirma que o desenvolvimento psíquico da criança é desencadeado quando esta passa a participar de uma atividade coletiva que lhe traz novas necessidades e exige dela novos modos de ação. É a participação na atividade que possibilita um ensino significativo. Desse modo, a teoria da atividade nos faz refletir sobre a intencionalidade do processo educativo.

Assumindo que o professor é aquele que concretiza os objetivos sociais objetivados no currículo escolar, pois define ações, seleciona instrumentos e avalia os processos de ensino e aprendizagem, Moura $(1992,2002)$ e Moura et al. (2010) propõem o conceito de atividade orientadora de ensino (AOE), que representa um elo entre a atividade do professor e atividade do aluno (ensino e aprendizagem). A AOE mantém a estrutura de atividade proposta por Leontiev,

[...] ao indicar uma necessidade (apropriação da cultura), um motivo real (apropriação do conhecimento historicamente acumulado), objetivos (ensinar e aprender) e propor ações que considerem as condições objetivas da instituição escolar. (MOURA et al., 2010, p. 96)

Ainda segundo Moura et al. (2010, p. 97):

Na AOE, ambos, professor e estudante, são sujeitos em atividade e como sujeitos se constituem indivíduos portadores de conhecimentos, valores e afetividade, que estarão presentes no modo como realizarão as ações que têm por objetivo um conhecimento de qualidade nova. Tomar consciência de que sujeitos em atividade são indivíduos é primordial para considerar a AOE como um processo de aproximação constante do objeto: o conhecimento de qualidade nova. A atividade, assim, só pode ser orientadora. Nesse sentido, a AOE toma a dimensão de mediação ao se constituir como um modo de realização de ensino e de aprendizagem dos sujeitos que, ao agirem num espaço de aprendizagem, se modificam e, assim, também se constituirão em sujeitos de qualidade nova.

Atentos aos pressupostos vigotskianos que nos alertam quanto à necessidade da análise dos processos em seu desenvolvimento (VIGOTSKI, 1998), assumimos que, para captar o objeto formação, primeiro é necessário colocá-lo em um movimento relativamente acessível. Nesse sentido, a teoria da atividade, bem como o conceito de AOE, constituíram-se como referência para organizar as ações de pesquisa que apresentamos. A organização de encontros com os professores de ensino médio de uma 
escola pública a partir dessa fundamentação teórica possibilitou criar situações que favorecessem a participação coletiva dos professores para agirem como sujeitos em atividade, na qual a linguagem se constituiu no principal instrumento mediador.

Vigotski (1989) estudou o papel da linguagem na formação da consciência. A partir daí, ele propõe uma diferenciação entre sentido e significado. Por exemplo, quando ouvimos a palavra bolacha, todos nós sabemos o significado dicionarizado dessa palavra. Porém, ao ouvi-la, posso me lembrar do lanche que minha avó fazia para mim em minha infância, e isso me faz atribuir um sentido diferente daquele atribuído por outras pessoas a essa mesma palavra. É na interseção dos vários sentidos atribuídos que se constrói o significado da palavra. Na interação com o meio e com outras pessoas, também temos a oportunidade de mudar os sentidos que atribuímos às coisas. Isso é interessante se pensarmos nos modelos de formação de professores em colaboração, pois, na interação, os sentidos podem se modificar, novas construções e novos conhecimentos podem tomar lugar, bem como indivíduos com qualidade nova.

Os pressupostos da teoria histórico-cultural nos direcionavam no sentido de instituir situações de ensino de forma intencional, em que havia a possibilidade real de ações partilhadas para a atividade pedagógica. Aí se situam as condições objetivas para que sujeitos interajam partilhando significado e, desse modo, podendo atingir nova síntese sobre um objeto de ensino. Assim, foi acordado com a direção da escola que os encontros com os professores seriam realizados durante o Horário de Trabalho Pedagógico Coletivo (HTPC). Optamos por desenvolver uma pesquisa de caráter colaborativo, supondo que a interação possibilitaria alcançar conhecimentos de qualidade nova e, portanto, sujeitos de qualidade nova. Temos que admitir que esse tipo de pesquisa não se inicia como colaborativa. Havia a intenção; Porém, foram necessários ao menos 2 anos para modificar a expectativa que os professores tinham sobre cursos de formação em modelo tradicional, como se os professores universitários tivessem respostas e soluções para seus problemas na escola.

\section{O objeto-formação: construção de} instrumentos para capturá-lo na essência

Segundo Moura (2004, p. 264), a formação é um fenômeno e investigá-la implica “compreender algo que não está dado, não está posto". Podemos acrescentar que é buscar algo que não está revelado explicitamente na observação das ações dos sujeitos ou dos produtos por eles produzidos. Assim, estamos de acordo com Kosik (1976, p. 12) quando nos afirma que:

Captar o fenômeno de determinada coisa significa indagar e descrever como a coisa em si se manifesta naquele fenômeno, e como ao mesmo tempo nele se esconde. Compreender o fenômeno é atingir a essência. Sem o fenômeno, sem a sua manifestação e revelação, a essência seria inatingível... 0 fenômeno não é, portanto, outra coisa senão aquilo que - diferentemente da essência oculta - se manifesta imediatamente, primeiro e com maior freqüência.

Kosik (1976, p. 30) ainda diz que "o todo não é imediatamente cogniscível para o homem, embora lhe seja dado imediatamente em forma sensível". 0 todo que se apresenta ao homem é caótico e obscuro. Segundo esse autor, é necessário que o homem faça um desvio para que possa conhecer e compreender o todo, pois "o concreto se torna compreensível através da mediação do abstrato, o todo através da mediação da parte" (p. 30).

Nesse sentido, aceitamos o pressuposto vigotskiano de que "estudar alguma coisa historicamente significa estudá-la no seu processo de mudança: esse é o requisito básico do método dialético" (VIGOTSKI, 1998, p. 85). Com isso, o autor nos alerta para considerarmos 
a realidade de modo a superar o dado aparente dos objetos ou fenômenos, o imediatamente revelado pelo aspecto sensorial.

Algumas pesquisas que visam a traçar determinado panorama relativo à formação de professores se restringem muitas vezes a utilizar entrevistas, questionários, registros de observações. Porém, ao investigar a formação de professores, é necessário buscar instrumentos que deem conta de apreender o movimento que leva o professor de uma qualidade a outra. Não podemos simplesmente utilizar um método que congele o objeto-formação, como se fosse uma fotografia. 0 fenômeno deve ser investigado em movimento, pois os sujeitos mudam de qualidade ao partilharem significados na ação educativa (MOURA, 2004).

Conscientes de que o objeto-formação é bastante complexo, sendo impossível observar a totalidade do fenômeno de uma só vez, ao assumirmos que o professor se forma nas interações com os pares, movido por motivos pessoais e coletivos, devemos atentar para a construção de instrumentos que deem conta de apreender o objeto formação em seu movimento e também considerar as suas múltiplas determinações. E aqui lembramos o que nos diz Sacristán (1991) sobre a profissão docente. Alerta o autor para o fato de que a profissão docente não detém a responsabilidade exclusiva sobre a prática educativa. A aula em si é perpassada pelas crenças e concepções que o professor tem sobre o ensino; sua prática é um elemento dentro da escola que faz parte de um sistema educativo, no qual existem, além de práticas educativas, também práticas concorrentes.

Ter como objeto de estudo a formação de professores é ter um objeto em contínuo movimento. Para investigá-lo, é preciso considerar sua dinamicidade e suas múltiplas determinações e interdependências. Sendo assim, os instrumentos usados para apreender objetos estáticos não funcionam nesse caso. Em termos de formação de professores, Moura (2004) afirma que, para compreendê-la, é necessário integrar-se ao ambiente próprio do professor como sendo parte do fenômeno que pode causar o movimento de formação. Para esse autor, no caso de desenvolvimento profissional do professor, trata-se de entender como as ações organizadas para a realização da educação escolar podem revelar esse desenvolvimento.

Ao nos apoiarmos na perspectiva histórico-cultural, que pressupõe que "o homem se faz ao produzir os seus objetos e que, ao produzir os seus objetos, ele produz também as suas significações, cuja expressão máxima é a palavra" (MOURA, 2004, p. 260), tomamos os professores como aqueles que lidam com o conceito como ferramenta e, sendo assim, necessitam entender precisamente seu objeto. Necessitam dar significado ao que ensinam para que seus alunos possam encontrar sentido naquilo que lhes dizem ser importante aprender. É na escola que ocorre a produção e a partilha de significados das ações dos indivíduos que participam da atividade educativa (o objeto do professor).

Apanhar e analisar o processo de formação, como vimos, requer instrumentos que de algum modo evidenciem os processos de mudança qualitativa possiveis nas ações educativas. Nesse sentido, encontramos no conceito de isolado proposto por Bento de Jesus Caraça (2002) o que nos parece ser bastante adequado. 0 autor propõe o conceito de isolado para analisar mudanças qualitativas delimitando parte de um todo de modo a tornar possivel acompanhar com mais objetividade os processos de mudança no seu interior.

Caraça (2002), ao discorrer sobre os fenômenos na dinâmica de sua formação, afırma que a realidade que o homem se esforça por apreender tem duas características básicas:

a) Interdependência: o autor assume que "todas as coisas estão relacionadas umas com as outras” (CARAÇA, 2002, p. 103). 0 mundo existe de tal forma que sempre podemos relacionar entre si fenômenos aparentemente distintos.

b) Fluência: o autor afırma, ao citar Heralito de Efeso, que tudo está em permanente movimento. "Todas as coisas, a todo momento se transforma, tudo flui, tudo devém” (p. 103). 
Apesar de reconhecer tais características, ele observa que, se aceitarmos a interdependência e a fluência, dificuldades e limitações se apresentarão no estudo de qualquer fenômeno físico ou natural.

Caraça (2002, p. 105) questiona:

[...] na impossibilidade de abraçar, num só golpe, a totalidade do universo, o observador recorta, destaca desta totalidade, um conjunto de seres e fatos, abstraindo de todos os outros que com eles estão relacionados.

É a essa seção da realidade, a esse conjunto que o autor chama de isolado, o que, segundo ele, contém certa margem de erro, pois não considera o restante da realidade. Assim, é importante escolher isolados que conservem vários fatores da realidade e que se interdependam e tenham influência marcante no fenômeno a estudar.

Na proposta de Caraça (2002), o aparecimento de inesperados é que dirá que o isolado não foi adequadamente escolhido, pois algum fator determinante não foi escolhido. Por ser arbitrário, o isolado pode ser constitutivo de outros isolados mais amplos que poderão servir de referencial para a análise de fenômenos mais complexos.

Quando iniciamos o trabalho, procurávamos satisfazer a necessidade de se fazer pesquisa com professores em seus contextos escolares visando a uma maior cientificidade, e não pesquisa sobre eles. Tínhamos dúvida se o que faríamos era uma intervenção, já que não apenas coletaríamos dados na escola, mas auxiliaríamos os professores sempre que solicitassem ajuda, levando subsídios teóricos e instrumentais, formando com eles uma comunidade de análise e reflexão. Tínhamos claro que não pretendíamos avaliar as práticas dos professores e oferecer critérios sob nosso ponto de vista externo. Não se tratava só de observar e registrar.

A metodologia utilizada aos poucos foi se constituindo numa pesquisa-ação colabora- tiva (IBIAPINA, 2008), na qual os sujeitos colaboram em prol de objetivos e metas comuns ao grupo e surgidos do contexto no qual atuam (universidade e escola). A pesquisa colaborativa visa criar uma cultura de reflexão e análise das práticas na escola.

Nas palavras de Pimenta (2006, p. 49):

A pesquisa não se limita a uma forma de ação (risco de ativismo): pretende-se aumentar o conhecimento dos pesquisadores ou o 'nível de consciência' das pessoas e dos grupos considerados.

Esse tipo de pesquisa não tem um formato inicial preestabelecido, mas vai se constituindo no processo, ao longo do percurso.

$\mathrm{Na}$ escolha do campo empírico do trabalho, buscamos selecionar uma escola dentre as que tínhamos um contato prévio já estabelecido, por meio das atividades de extensão realizadas pelo Centro de Ensino Integrado de Química (CEIQ). A escolha da escola estadual se pautou nos seguintes critérios:

a) alguns de nossos alunos de licenciatura em química já haviam realizado estágio nela, sendo muito bem recebidos pelos professores, coordenadores e diretores;

b) a coordenadora do ensino médio já participava de oficinas pedagógicas com uma outra colega pesquisadora;

c) os professores eram na maioria jovens (30 a 40 anos) e demonstraram que gostariam que a universidade de alguma forma apoiasse e discutisse suas práticas;

d) a professora de química era ex-aluna do curso de licenciatura em química e colega da pesquisadora.

Assim que o projeto foi apresentado ao diretor da escola, ele se interessou e pediu que combinássemos com a coordenadora como poderíamos cuidar do desenvolvimento. A coordenadora também achou interessante a ideia de formar um grupo de estudos sobre temas relacionados à educação ambiental na escola. Ela sinalizou que poderíamos utilizar uma parte do 
HTPC para esses estudos, pois não havia a possibilidade de os professores serem dispensados em outros horários para isso.

Inicialmente, realizou-se uma apresentação do projeto em PowerPoint para os professores da escola e discutiu-se a intenção de formar o grupo de estudos. Naquele momento, percebemos que, apesar de nossas pesquisas anteriores terem se voltado para os professores de química, seria inviável que no grupo em formação tivéssemos somente professores dessa área. Além disso, professores de biologia, história, filosofia, português, inglês e matemática estavam presentes e demonstraram interesse em participar do grupo. Portanto, levando em conta o caráter interdisciplinar da educação ambiental, consideramos que um grupo com formação heterogênea enriqueceria as discussões. Então, ficou acordado que usaríamos, para nossos estudos e discussões, uma hora durante algumas reuniões de HTPC, sendo que, quando fosse necessário, usaríamos as duas horas. Assim se configurou o grupo formado por 12 professores das diferentes disciplinas ministradas no ensino médio, 3 alunos de licenciatura em química da nossa instituição e 1 de nós pesquisadores.

\section{Organização dos encontros}

0 tema ambiental passou a ser o eixo articulador a partir do qual cada encontro foi organizado como uma atividade orientadora de ensino. Textos foram selecionados, lidos e estudados. Além disso, também selecionamos vídeos, os quais foram assistidos e depois discutidos coletivamente. Realizou-se uma média de seis encontros semestrais desde então. Os encontros foram gravados em vídeo e as filmagens serviram de fontes de informação, bem como as atas dos encontros, as anotações da pesquisadora e dos alunos de licenciatura em química participantes do projeto, pequenas narrativas e entrevistas abertas. Após uma leitura flutuante dos dados, procurou-se identificar categorias emergentes, nesse caso, que poderiam se configurar como categorias de análise.
Numa AOE, cria-se uma estrutura que favoreça a interação entre sujeitos, a partir de e mediada por determinado conteúdo, havendo então negociação de significados e o objetivo de encontrar soluções para dado problema coletivo. Dentre as ações realizadas para cada encontro, destacamos: leituras, vídeos, discussão entre os pares, busca de reflexões amplas, identificação dos diversos fatores envolvidos nos temas. Após momentos de estudo sobre temas ambientais, o grupo de professores começou a organizar coletivamente AOEs para serem realizadas com os estudantes. Tanto o planejamento quanto a realização de tais AOEs na escola foram gravados e configuraram-se como dados para estudar a formação, pois o modo de realizá-las permitia colocar em movimento acessivel as ações dos professores a serem analisadas.

Cada encontro durava uma hora. Eram organizados como atividades, sendo compostos por ações como:

a) leitura prévia de um texto sobre um tema ambiental, seguida de discussão e debate pelos membros participantes ( 5 professores de ensino médio, 1 professora universitária e 2 licenciandos em química);

b) exibição de vídeos sobre aquecimento global, seguida de debate sobre a utilização do mesmo em sala de aula;

c) elaboração de atividades orientadoras de ensino versando sobre temas ambientais e integradoras das disciplinas de química, física, biologia, português e filosofıa (levando em conta a área de atuação dos professores participantes);

d) desenvolvimento das atividades com os alunos.

\section{Alguns dados e suas análises}

Procurou-se observar principalmente ações e reflexões dos professores que revelassem mudança (qualidade nova) na concretização do projeto de formação. Isso poderia ser revelado no que escreviam, nas intervenções em reuniões coletivas, durante os encontros. Analisando os 
dados recolhidos, pode-se recortar alguns isolados que continham a essência do fenômeno estudado. A análise desses isolados pode ser feita por meio da escolha de cenas que constituem o que Moura (2004) chama de episódios. Apresentamos a seguir alguns desses episódios de modo a evidenciar os processos interativos que estão ocorrendo e como neles são partilhados significados. Nos episódios a seguir temos exemplos de que se pode notar nas discussões, em algumas situações, a modificação do sentido atribuído a alguns conceitos pelos professores.

Episódio 1: Foi retirado de um encontro em que o grupo discutiu problemas ambientais globais e regionais. Durante a discussão, a professora de história pode rever seu conhecimento sobre a afirmação de que a Amazônia é o pulmão do mundo. Aparentemente, ela amplia e modifica seu conhecimento por meio da reflexão a partir da fala dos colegas. Nesse momento, pode-se considerar que um conhecimento de qualidade nova é produzido; é a formação em curso tomando forma. Veja o relato a seguir:

Foi citado o desmatamento na Amazônia e a seca, e uma professora de história fez um comentário sobre a Amazônia ser o pulmão do mundo. Os outros professores explicaram a ela que este conceito não é correto, pois as algas é que são as responsáveis por grande parte da produção do oxigênio. Também foi comentado pelos professores que a TV não é um meio de comunicação confiável, pois na mídia são passados muitos conceitos errados. Uma professora citou como exemplo o álcool, que, atualmente, nos postos de combustíveis, passou a ser chamado de etanol, e na mídia estavam falando que essa substância era usada apenas como combustível. (Relato do encontro do dia 11 de maio de 2010)

Episódio 2: Retirado de um encontro em que o objetivo do grupo era planejar atividades orientadoras de ensino sobre lixo e água, as quais fariam parte da Semana de Educação para a Vida e envolveriam todos os alunos de ensino médio.
As atividades seriam realizadas em três dias consecutivos na escola. Durante o encontro, a professora de química demonstrou preocupação com a continuidade ou retomada das atividades, questionando: "o que os alunos vão fazer depois em sala?”. A professora ainda afirmou que "cada professor nesse período fora das palestras vai ter que pensar o que vai fazer". Para ela, em uma semana especial, tudo deve ser planejado em termos de cronograma antes e depois de cada atividade. Sua fala reúne elementos de planejamento de uma atividade orientadora de ensino, uma vez que explicita a intencionalidade da atividade, considera as ações do aluno e ao mesmo tempo do professor dentro dessa atividade, cogita a continuidade e a articulação de cada ação com as outras que estão sendo planejadas para a semana temática.

Episódio 3: Retirado de um encontro em que o grupo discutiu a utilização de agrotóxico. Esse episódio fez parte da monografia apresentada por Jussara Costa, aluna de licenciatura em química da da Faculdade de Filosofia, Ciências e Letras de Ribeirão Preto, Universidade de São Paulo, em dezembro de 2010. Ao discutir sobre a possibilidade de produzir alimentos sem a utilização de agrotóxicos, percebeu-se primeiramente a vinculação da questão com a quantidade de alimento a ser produzida em razão do número de pessoas a ser atendidas:

Prof. de biologia: Diante do que ele fala no texto... na questão de suprir a fome...

Prof. de sociologia: Pra produzir em larga escala!

Prof. de biologia: Não tem! Não dá! Mesmo em relação às pragas biológicas que você tem que, de imediato, acabar com essas pragas pra que os alimentos possam ser produzidos totalmente sem... (pausa) pro tanto de gente que tem no mundo! Totalmente sem eu acho que não! [Ao mesmo tempo, a professora nega com a cabeça]

A produção em larga escala para saciar a fome no mundo foi mencionada pela professora de biologia. Esse discurso está relacionado ao 
que chamamos de mito salvacionista da ciência e da tecnologia, ou seja, atribui-se à ciência e à tecnologia toda a responsabilidade por solucionar problemas envolvendo a humanidade. A perspectiva salvacionista da fome no mundo não leva em consideração os aspectos sociais, políticos e econômicos que estão embutidos nessa questão.

A questão é complexa e não deve se limitar a respostas simplistas como apenas Sim ou Não para perguntas que envolvam o uso de agrotóxicos para produção de alimentos. Devemos considerar as complexidades históricas, sociais, econômicas e políticas que envolvem essa questão. Acabar com a fome no mundo depende, então, de mudanças de comportamento das pessoas e também de vontade política, de reestruturação do sistema financeiro, de mudanças no modo de funcionamento do mercado mundial.

Pelos diálogos, percebeu-se que os professores vincularam o uso ou não de agrotóxico à condição de produção. Por exemplo, citaram que, para a agricultura de subsistência, em pequena escala, não haveria necessidade da utilização de agrotóxico. Porém, para a produção em larga escala, a utilização do agrotóxico seria fundamental. Um professor de física e outro de biologia citaram as culturas de cana e soja. 0 discurso do professor de física orientou-se pela quantidade de alimento a ser produzida e pela finalidade dessa produção.

Diante do posicionamento do grupo, indagamos:

Quando se diz que não tem jeito [referindo-me à impossibilidade de produzir alimentos sem agrotóxico], fico pensando se realmente não tem jeito ou se não tem outra resposta ou se nós não conhecemos outra resposta.

A seguir, apresentamos alguns diálogos ocorridos na discussão:

Prof. de sociologia: 0 que eu acho que complica aí nesse caso é contextualizar para uma sociedade capitalista.

Prof. de biologia: Também!
Prof. de sociologia: Existem comunidades de permacultura, subsistência, mas ao mesmo tempo poucos têm terra e o incentivo à agricultura é muito pequeno, é impossível realmente. Entende? Se a intenção é produzir em larga escala, âmbito maior, nesse contexto fica difícil! Agora, se existissem incentivos a permacultura, comunidade, produção menor, e se tivesse uma divisão igualitária e produtiva da terra poderia, mas nossa realidade é capitalista, latifundiária. Para nossa realidade não se encaixa mesmo! Prof. de português: Também, assim, conscientizar as pessoas de que se elas tiverem um pedacinho de terra no seu quintal, elas teãor a sua hortinha! Porque no passado a gente tinha, ali você colhia muita coisa e hoje [pausa] como foi falado na última aula [encontro] parece que a folha [da árvore] é lixo. Então hoje nós queremos varrer tudo, queremos limpar tudo, não conseguimos associar o valor que tem o lixo orgânico né? Para que a gente dali mesmo fazer o adubo, para a gente estar produzindo algo. A maioria das casas tem um pedacinho de terra. Todo mundo tinha um pé de couve, tomate, bananeira... Hoje ninguém tem mais! Aliás, tem criança que nunca viu uma bananeira... Nunca viu uma bananeira, nunca viu nada! Nada! Um pé de laranja! Às vezes, a pessoa nunca foi em uma lavoura!

A construção coletiva do discurso possibilita perceber a presença de diferentes pontos de vista. A professora de sociologia, ao introduzir em seu discurso o problema como sendo "contextualizar para uma sociedade capitalista”, considera que a resposta não pode ser simplista. Seu discurso é caracterizado pela complexidade do tema, considerando os aspectos políticos, econômicos e sociais.

Assim, a professora de sociologia evoca o que podemos identificar como sendo a complexidade e a interdependência de conceitos para uma questão aparentemente simples. Ficou clara a necessidade de contextualizar 
os fenômenos em estudo, pois vivemos num mundo em que os interesses capitalistas se sobressaem em relação ao bem social. As causas, as condições que estavam implícitas nas respostas dos outros professores foram apontadas por essa professora de sociologia. Assim, é importante retomar a formação de conceitos, observando seus nexos conceituais.

Da mesma forma como aconteceu na reunião em que a professora de história reelaborou seu conhecimento, produzindo um conhecimento de qualidade nova, diante do que lhe foi dito por outros colegas de que a Amazônia não é o pulmão do mundo, também podemos observar o papel do compartilhamento de significados em situação de planejamento de atividades educativas no caso da professora de sociologia. Esta desdobrou o tema agrotóxico no modo de produção capitalista, fazendo com que os outros professores pensassem sobre isso e possibilitando que eles identificassem em seus discursos a contextualização do problema, como a professora de biologia, que concordou dizendo "Também". Assim, o contexto que estava implícito nas falas dos professores foi identificado por ela alterando o discurso dos demais, pois, quando ela aponta esse problema, está contribuindo para o aprendizado dos outros professores.

Dessa forma, se considerarmos que, nos processos interativos promovidos pela necessidade de organizar as atividades de ensino, os sujeitos partilharam significados, podemos afirmar que a professora de sociologia favoreceu uma apropriação de conhecimento que possibilitou nova qualidade àquele que o adquiriu. Fica evidente o pressuposto de que o desenvolvimento individual ocorre em um ambiente social e na relação com o outro, tal como nos ensina Vigotski (1998).

A pesquisa colaborativa cria condições para que todos os sujeitos envolvidos possam aprender, de alguma forma. Por isso, é fundamental haver um espaço-tempo (HTPC) que possibilite o diálogo entre professores de diversas áreas de conhecimento. Lembrando autores discutidos na fundamentação teórica deste artigo, na reunião de HTPC estão sendo vivenciados os princípios de formação da consciência, movimento que vai do interpsíquico para o intrapsíquico. No momento em que os professores estavam convencidos de uma resposta simples sobre a possibilidade de conceber um mundo sem agrotóxico, a experiência da professora de sociologia mobilizou uma nova discussão: os aspectos sociais envolvidos na utilização dos agrotóxicos

\section{Considerações finais}

Para se formar o educador ambiental é necessário que haja coerência entre esse fim, o contexto de formação e as metodologias utilizadas. A formação do educador ambiental pressupõe um ambiente em que todos tenham voz e possam trocar experiências, rever seus conhecimentos e produzir novos sentidos a partir de uma perspectiva crítica. A formação da comunidade de aprendizagem na escola parceira forneceu um contexto propício para a formação dos professores em educação ambiental. Pudemos comprovar que o Horário de Trabalho Pedagógico Coletivo, quando planejado e organizado, pode intencionalmente contribuir para a formação de professores.

Muitos programas de formação de professores falham por se dedicarem aos elementos que compõem o trabalho docente de forma pontual e não articulada. Em alguns casos, abordam somente a atualização de conhecimentos científicos e técnicos; em outros, a metodologia de ensino desses conhecimentos. Reúnem professores de diferentes escolas e propõem que planejem atividades envolvendo metodologias variadas, mas sem considerar as condições objetivas da realidade escolar em que cada professor atua.

A teoria da atividade nos deu subsídios tanto no que se refere ao ensino - visto que serviu de embasamento para a organização dos encontros, sempre levando em conta a intencionalidade da formação -, quanto em relação ao aspecto metodológico, para colocar em mo- 
vimento o objeto-formação. $\mathrm{Na}$ interação entre os sujeitos, pode-se perceber a ampliação de seus pontos de vista e mudanças significativas de sentidos relacionados a temas ambientais. Ao evocar um pensamento, uma reflexão, o sujeito possibilita que os demais revisitem seus posicionamentos e conhecimentos. Assim, conhecimento de qualidade nova e, consequentemente, indivíduos com qualidade nova são formados.
Os instrumentos escolhidos para colocar o objeto-formação em movimento e também para apreendê-lo em sua essência mostraram-se adequados. A concepção dos isolados de Caraça (2002) foi pertinente para perceber indícios da formação ocorrendo no contexto colaborativo. Os vários isolados, numa etapa posterior, poderão ser revelados por novos episódios.

\section{Referências}

BARDIN, Laurence. Análise de conteúdo. Lisboa: Edições 70, 2006.

CARAÇA, Bento de Jesus. Conceitos fundamentais da matemática. Lisboa: Gradiva, 2002.

DUARTE, Newton. Formação do indivíduo, consciência e alienação: 0 ser humano na psicologia de A. N. Leontiev. Cadernos Cedes, Campinas, v. 24, n. 62, p. 44-63, 2004.

GIUBINA, Fernanda Furlan; CAMPOS, Maria Lúcia A. de M.; ABREU, Daniela Gonçalves de. A formação ambiental segundo a percepção de licenciandos em química. In: ENCONTRO NACIONAL DE ENSINO DE QUÍMICA, 14., 2008, Curitiba. Anais... Curitiba: Universidade Federal do Paraná, 2008.

GOLDER, Mario. Leontiev e a psicologia histórico-cultural: um homem em seu tempo. São Paulo: Xamã, 2004.

IBIAPINA, Ivana M. L. de Melo. Pesquisa colaborativa: investimento, formação e produção de conhecimentos. Brasília: Liber, 2008.

KOSIK, Karel. Dialética do concreto. Rio de Janeiro: Paz e Terra, 1976.

LEONTIEV, Alexei. 0 desenvolvimento do psiquismo. Lisboa: Horizonte, 1978.

MOURA, Manoel Oriosvaldo de. A construção do signo numérico em situação de ensino. Tese (Doutorado em Educação) Faculdade de Educação, Universidade de São Paulo, São Paulo, 1992.

. A atividade de ensino como formadora. In: CASTRO, Amélia Domingues de; CARVALHO, Anna Maria P. de (Orgs.). Ensinar a ensinar: didática para a escola fundamental e média. São Paulo: Pioneira Thompson, 2002. p. 143-162.

Pesquisa colaborativa: um foco na ação formadora. In: BABOSA, Raquel L. Leite (Org.). Trajetórias e perspectivas da formação de educadores. São Paulo: Unesp, 2004. p. 257-284.

MOURA, Manoel Oriosvaldo de et al. A atividade orientadora de ensino como unidade entre ensino e aprendizagem. In: MOURA, Manoel Oriosvaldo (Org.). A atividade pedagógica na teoria histórico-cultural. Brasília: Liber, 2010. p. 81-110.

PIMENTA, Selma Garrido. Pesquisa-ação crítico-colaborativa: construindo seu significado a partir de experiências na formação e atuação docente. In: PIMENTA, Selma Garrido; GHEDIN, Evandro; FRANCO, Maria Amélia S. Pesquisa em educação: alternativas investigativas com objetos complexos. São Paulo: Loyola, 2006. p. 25-64.

SACRISTÁN, José Gimeno. 0 currículo: uma reflexão sobre a prática. 3. ed. Porto Alegre: Artmed: 2000.

Consciência e a ação sobre a prática como libertação profissional dos professores. In: NÓVOA, António (Org.). Profissão professor. Porto: Editora Porto, 1991. p. 63-92. 
SFORNI, Marta Sueli de Faria. Aprendizagem conceitual e organização do ensino: contribuições da teoria da atividade. Araraquara: JM, 2004.

VIGOTSKI, Lev S. Pensamento e linguagem. São Paulo: Martins Fontes, 1989.

A formação da mente: o desenvolvimento dos processos psicológicos superiores. São Paulo: Martins Fontes, 1998.

. A construção do pensamento e da linguagem. São Paulo: Martins Fontes, 2001.

Recebido em: 09.11.2012

Aprovado em: 22.05.2013

Daniela Gonçalves de Abreu é professora da área de Ensino de Química do Departamento de Química da Faculdade de Filosofia, Ciências e Letras de Ribeirão Preto da Universidade de São Paulo (USP) e líder do Grupo de Formação, Ensino e Pesquisa em Educação Ambiental (GFEPEA).

Manoel Oriosvaldo de Moura é professor titular da Faculdade de Educação da Universidade de São Paulo (USP) e líder do Grupo de Estudos e Pesquisas sobre Atividade Pedagógica (GEPAPe). 